COMENTARIOS

LEGISLATIVOS 



\section{LAS REFORMAS CONSTITUCIONALES EN MATERIA PENAL}

TODA REFORMA LEGISLATIVA, empezando por la de la ley fundamental, para que sea plenamente eficaz requiere del fortalecimiento de la cultura de legalidad y de respeto a la ley. Esta cultura tiene, por lo menos, dos dimensiones. La primera, la más importante, consiste en que los gobernados sepan con toda claridad cuáles son las consecuencias por violar una norma jurídica $y$, antes que eso, que puedan percibir plenamente que el hecho de violar una ley va a tener consecuencias jurídicas, sobre todo si esas leyes se encuentran dentro del marco penal; que sean conscientes que puede y debe haber una consecuencia en nuestra libertad personal, en nuestros derechos, en nuestra prerrogativas, porque el hecho de que esa convicción no esté en el ánimo de la inmensa mayoría de los mexicanos supone un desprecio por violar un mandato imperativo y, desde luego, es una fuente inagotable de impunidad. Así, impunidad, delincuencia e inseguridad pública se van potenciando una a la otra, hasta llevarnos a situaciones tan delicadas como las que ha vivido nuestro país en la última década. La segunda dimensión, que sobre todo es perceptible en el ámbito penal, es explicarle a nuestra sociedad de la manera más simple, más llana posible, en qué consisten nuestras normas penales, cómo es nuestro proceso penal.

La presente reseña se refiere a las últimas reformas constitucionales en materia penal publicadas en el Diario Oficial de la Federación el 8 de marzo de 1999, a las cuales se une la expedición de ocho distintos decretos que contienen dos nuevas leyes completas y reformas a doce distintos ordenamientos jurídicos. Todo esto sucedió entre junio de 1998, cuando se publicó la Ley del Registro Nacional de Vehículos, y el 8 de marzo de 1999, cuando se publicaron en el mismo Diario Oficial de la Federación un conjunto de reformas al Código Penal y al Código de Procedimientos Penales que vienen a dar concreción a la reforma de los artículos 16 y 19 de la ley fundamental. El universo de ordenamientos jurídicos reformados es profundamente significativo. Dentro de los 12 instrumentos jurídicos modificados se encuentran el Código Penal, el 
Código Federal de Procedimientos Penales, el Código de Justicia Militar, la Ley de Amparo, la Ley Federal de Armas de Fuego y Explosivos, la Ley de Normas Mínimas sobre Readaptación Social de Sentenciados, la Ley de Instituciones de Crédito, la Ley General de Organizaciones y Actividades Auxiliares del Crédito, la Ley Federal de Instituciones de Fianzas, la Ley General de Instituciones y Sociedades Mutualistas de Seguros, la Ley de Mercado de Valores y la Ley de los Sistemas de Ahorro para el Retiro.

Esta reforma penal ha sido una de las más ambiciosas que hemos visto en la etapa moderna de México.

Para una mejor comprensión del sentido y alcances de esta gran reforma penal, señalamos a continuación algunos antecedentes y circunstancias dentro de las cuales se encuentra inmersa.

Los últimos años se han caracterizado por un acelerado crecimiento de los índices delictivos que ha generado un tenso ambiente de inseguridad. La delincuencia común y la llamada organizada han expandido visiblemente su acción en las grandes ciudades y en los medianos centros de población. Los esfuerzos gubernamentales para frenar el fenómeno han sido constantes, aunque no siempre exitosos.

El Plan Nacional de Desarrollo reconoció que nuestro marco normativo e institucional no era del todo adecuado a las expectativas y a las condiciones actuales, que subsistían atrasos, vicios y carencias en materia de seguridad pública, procuración e impartición de justicia, combate a la corrupción e impunidad, seguridad jurídica y reconocimiento a los derechos fundamentales, en especial en agravio de los grupos sociales más vulnerables, y que en estas materias prevalecía la desconfianza social en las instituciones, programas y autoridades responsables de la implantación de estos últimos.

El fenómeno delictivo no es exclusivo de nuestra sociedad ni de este tiempo, las estadísticas del comportamiento delictivo en países altamente desarrollados, que cuentan con mayores recursos económicos para combatirlo, también se han visto incrementadas, sin embargo, en nuestro país su presencia es cada día más amenazadora, ya que muchas de sus manifestaciones traspasan las fronteras nacionales y se insertan en complejas redes internacionales perfectamente organizadas que disponen de vastos recursos económicos y tecnológicos, enorme movilidad para actuar desde 
los más diversos y distantes puntos geográficos y un poder corruptor cada vez más alarmante y peligroso.

La delincuencia organizada dedicada al narcotráfico, al tráfico de personas y armas, al secuestro, al robo en gran escala y a la comisión de los delitos llamados de cuello blanco que no por no ser violentos son menos lesivos, es una de las manifestaciones más serias que presenta este fenómeno y la que sin duda ha aportado las mayores cuotas de violencia, peligrosidad e impunidad.

Si se analiza el desarrollo del fenómeno delictivo en los últimos lustros, se puede apreciar con claridad su alarmante crecimiento continuo: en 1980, se pusieron a disposición del juez penal, tanto en el fuero común tanto como en el federal, a 76,166 presuntos delincuentes; para 1995 la cifra alcanzó los 180,163, destacándose que el mayor crecimiento se observó en el periodo de 1990 a 1995. Estas cifras ilustran sólo una parte del problema, ya que únicamente se refieren al número de personas a quienes se les dictó un acto de término constitucional.

Debe considerarse que el número de delitos que se comete es muy superior al número de denuncias. Según datos del Sistema de Seguridad Pública, en 1997 se denunciaron aproximadamente 1'500,000 delitos, que condujeron a la emisión de un poco menos de 150,000 órdenes de aprehensión, de las cuales sólo se cumplió el 85\%. El dato implica que de ese millón y medio de delitos denunciados sólo en aproximadamente $8 \%$ de los casos un presunto delincuente fue puesto a disposición de la autoridad judicial.

En el fuero federal se incrementó significativamente el número de averiguaciones previas despachadas durante los últimos quinquenios, al pasar de 47,346 en 1980, a 73,533 en 1995. Por lo que toca a procedimientos penales concluidos la cifra se incrementó de 7,563 en 1980, a 26,089 en 1995.

Si del universo total de delitos cometidos sólo una parte se denuncian; si de las averiguaciones previas integradas sólo una parte se consignan; si de las averiguaciones consignadas sólo en el $80 \%$ de los casos se obtienen órdenes de aprehensión; si de las órdenes obsequiadas sólo un pequeño número se ejecutan; si de los sujetos aprehendidos o consignados ante el juez no en todos los casos se dicta un auto de formal prisión o de sujeción a proceso y un número importante de detenidos logran su libertad caucional e, incluso, evaden la acción de la justicia y, finalmente, 
si del número de personas que enfrentan un proceso penal no en todos los casos se obtienen sentencias condenatorias, el panorama no puede ser más desalentador; la realidad se nos revela en forma brutal: estamos conviviendo cotidianamente con delincuentes.

El fenómeno delictivo es complejo y multicausal por lo que se explica como resultado de diversas variables que interactúan en el entramado social. En el ámbito nacional se han identificado como las principales causas de la comisión de delitos y conductas infractoras, entre otras, el deterioro de las condiciones económicas y sociales; la agudización de la pobreza extrema, la inestabilidad laboral, desempleo y subempleo; la insatisfacción de las necesidades básicas de amplias capas de la población; el acceso marginal a las oportunidades de educación, servicios de salud y habitación; la deserción escolar en todos los niveles; la violencia intrafamiliar; la desintegración familiar, la difusión de programas con un alto contenido de violencia en los medios masivos de comunicación en barrios marginados.

Al lado de estos factores de orden sociológico se identifica otro vinculado con la eficiencia del sistema de procuración e impartición de justicia que es la existencia de ciertas condiciones legales que han favorecido a la impunidad.

En efecto, en los últimos años la sociedad mexicana ha vivido dentro de un círculo vicioso: la delincuencia se ha desatado, entre otras causas, como consecuencia de la impunidad y, a la vez, la impunidad ha favorecido la delincuencia.

La desconfianza comprensible de la ciudadanía en las instituciones se explica por el gran número de ocasiones en las que un presunto responsable es conducido ante el Ministerio Público o ante el juez y es dejado en libertad en unas cuantas horas. No castigar a quienes atentan contra la integridad física de las personas o su patrimonio, a quienes a través de grupos delictivos perfectamente organizados se dedican a cometer los actos más violentos, nocivos y aberrantes, ha propiciado amplios márgenes de impunidad en los que desde hace algunos años se han movido con cierta libertad los infractores del orden social.

Para el grueso de la población es difícil comprender y aceptar que esta situación no deriva en todos los casos de corrupción o falta de compromiso del Estado para atender el serio problema de la delincuencia y la 
inseguridad, sino que en muchos casos también estos problemas surgen de la propia legislación penal que nos ha regido.

Este problema es resultado, en buena medida, de los cambios adoptados en la Constitución de 1993 que, con un pronunciado sentido garantista, definieron importantes derechos en beneficio de los indiciados y, al no señalar mayores garantías en favor de las víctimas u ofendidos, rompieron el equilibrio procesal en beneficio exclusivamente del probable responsable.

Al margen de lo que había sido nuestra evolución histórico jurídica, en 1993 se realizaron una serie de reformas y adiciones constitucionales que derivaron en el tránsito, un tanto artificial, de nuestro sistema de enjuiciamiento penal de la corriente causalista a la corriente finalista de la acción penal, dos corrientes de pensamiento doctrinal distintas y que sólo pueden operar eficientemente bajo determinadas condiciones procedimentales.

La iniciativa de reformas y adiciones de 1993 se gestó en la Cámara de Diputados de la LV Legislatura del Congreso de la Unión. En esa ocasión, originalmente se planteó reformar los artículos 16, 20 y 119 de la Constitución, pero en tanto se discutían estas reformas en las Comisiones Unidas de Gobernación y Puntos Constitucionales y de Justicia, un grupo de diputados de las mismas incorporó a la iniciativa una reforma al artículo 19 y la derogación de la fracción XVIII del artículo 107 de la Constitución.

Estas reformas al sistema de enjuiciamiento penal tuvieron como propósito establecer un régimen que brindara mayores garantías al inculpado, mejorara la justicia penal a través del equilibrio entre los principios de seguridad jurídica y libertad, y equilibrara las facultades de la autoridad para perseguir y sancionar el delito con las garantías procesales del indiciado.

En lo que toca al artículo 16 constitucional ha de señalarse que en aquel entonces se adicionaron dos párrafos a los originalmente previstos, en el segundo de los cuales se reguló el libramiento de la orden de aprehensión precisando los elementos de fondo que debían cumplir las autoridades judiciales para girarla, con lo que se sustituyó la figura del cuerpo del delito por los elementos del tipo penal.

Es aquí donde se produjo el cambio de fondo y se adoptó en nuestro sistema penal la tesis finalista de la acción penal. Para ser congruente 
con dicha propuesta, se modificó también el artículo 19 constitucional, haciéndose equivalentes los elementos exigibles para librar una orden de aprehensión con los requeridos para emitir un auto de formal prisión.

Se regularon, también, las facultades del Ministerio Público para ordenar la detención de un sujeto en delito flagrante, o bien en casos urgentes tratándose de delitos graves si existía riesgo fundado de que el indiciado pudiera sustraerse de la acción de la justicia, así como las facultades del juez de ratificar o no dichas detenciones y actuar en consecuencia.

Se definió también que el término máximo del que dispondría el Ministerio Público para efectuar una investigación con el detenido sería de 48 horas, que a decir de los legisladores era suficiente para la integración de la averiguación correspondiente, sobre todo considerando que el plazo que se le había concedido al juez en términos del artículo 19 constitucional para valorar el acervo probatorio era de 72 horas y que el plazo también corría en beneficio de la defensa del indiciado. Se estableció la excepción para el caso de delincuencia organizada.

Cabe destacar sobre este particular que en muchos países que siguen la corriente finalista de la acción penal, la investigación con el detenido que se efectúa — por cierto con autoridades judiciales - lleva varios días, semanas o en ocasiones meses, ello debido a que por su naturaleza está implícito el gran peso del procedimiento penal.

En cuanto al artículo 19 constitucional, se estableció que para emitir autos de formal prisión deberían aparecer datos suficientes que acreditasen los elementos del tipo penal del delito que se le imputaba al detenido y que hicieran probable su responsabilidad penal.

El dictamen de las Comisiones, motivo de la reforma de 1993, se dirigió a la necesidad de compatibilizar la exigencia de los extremos de prueba que rigen para la orden de aprehensión con los del auto de formal prisión o, en su caso, de sujeción a proceso, buscando superar el complejo término de cuerpo del delito por el concepto de la acreditación de los elementos que integran el tipo penal, con lo que se clasificaron los requisitos que debían ser considerados por el juez para fundar y motivar su auto de formal prisión o de sujeción a proceso, y de esta manera se fortalecería la seguridad jurídica de los gobernados, al puntualizarse la obligación por parte de la autoridad de verificar la existencia del hecho delictuoso, además de la probable responsabilidad del inculpado. 
La reforma, sin embargo, fue mucho más allá de la suspensión del complejo término de cuerpo del delito por el concepto de la acreditación de los elementos que integran el tipo penal, ya que este cambio no se circunscribió a una mera cuestión semántica, sino que introdujo un nuevo sistema de enjuiciamiento penal muy explorado en diversos países del orbe y que funciona con eficacia dentro de contextos procedimentales muy distintos al nuestro, es decir, se adoptó una nueva forma de hacer justicia penal con abstracción de las condiciones que la hacen viable en otras latitudes.

A partir de este momento se abandonó en nuestro país la diferenciación de los requisitos para librar órdenes de aprehensión y para emitir autos de sujeción a proceso o de formal prisión, con lo que las exigencias técnicas para que las instituciones procuradoras de justicia pudieran consignar una indagatoria y obtener una orden de aprehensión y así, una vez detenido el sujeto, conseguir un auto de procesamiento, es decir, las etapas de averiguación previa y de preinstrucción se convirtieron en la práctica en un procedimiento cuasi jurisdiccional previo y sumario, desnaturalizando su función y generando un severo desequilibrio en las etapas procedimentales.

Por lo que toca al artículo 20, el precepto reguló con gran discrecionalidad el otorgamiento de la libertad provisional bajo caución, señalándose, incluso, que ésta podría ser disminuida por el juez en ciertos supuestos, todo ello en beneficio del inculpado.

El mismo dictamen motivó la propuesta de modificación de la siguiente forma: se buscó conciliar este derecho del inculpado con el interés de la víctima o el ofendido a que se le garantizara el monto estimado de la reparación del daño, sin embargo, en aquellos casos en que existiere un conflicto grave entre estos dos intereses, en los términos que señalare el legislador, se debería preferir el de la libertad de quien no ha sido declarado culpable sobre aquel interés que protege a la víctima, en razón del principio de presunción de inocencia y de preponderancia de la libertad frente a los bienes tutelados por los delitos que alcanzaron genéricamente este beneficio. En todo caso se debería pretender afectar lo menos posible al interés que se sacrificaba.

Como se observa, estas reformas pretendieron ampliar significativamente la esfera de derechos de los inculpados a través del establecimiento de estrictos requisitos constitucionales para poder privarlos de su libertad, 
lo cual se explica en un Estado de derecho como el nuestro en términos de respeto a los derechos humanos, pero no se justifica cuando frente a los derechos de las víctimas, de los ofendidos y de la sociedad misma, se privilegian los del probable responsable en detrimento de aquéllos.

Las implicaciones de las reformas a los artículos 16 y 19 constitucionales, aunadas a las condiciones para el otorgamiento de la libertad caucional, fueron variadas. La más importante, por el impacto que produjo tanto en el desarrollo del proceso penal cuyas etapas perdieron su sentido y finalidad original — alterándose en detrimento de la justicia - como en el ámbito social, debido a la percepción de ineficiencia en las autoridades, corrupción en la prosecución e injusticia en la ley, fue la facilitación de ciertos espacios de impunidad.

En nuestro país, antes de 1993, los extremos procesales que debían de probarse eran la existencia del cuerpo del delito, entendido como el conjunto de elementos objetivos o materiales que constituían la descripción típica del ilícito (por lo que la conducta debía de encuadrar perfectamente en la hipótesis penal para ser considerada delito), y la probable responsabilidad; el dolo o la culpa, elementos preferidos a la culpabilidad, se probaban durante el proceso.

Esto es, el cuerpo del delito estaba constituido por la tipicidad por lo cual su comprobación requería que la conducta del sujeto activo del delito objetivara todos y cada uno de los elementos del tipo, resultando necesario constatar el nexo causal entre el resultado típico y la conducta desplegada por el agente, por lo que es correcto afirmar que la conducta y la tipicidad pertenecían al cuerpo del delito, mientras que la antijuricidad y la culpabilidad eran parte de la responsabilidad penal; es por ello que atribuir la causación del resultado a una persona era una cuestión circunscrita a la responsabilidad.

A partir de 1993 la situación fue muy diferente, ya que el sistema implantado partió de un concepto final de acción que ubica el dolo y la culpa (elementos subjetivos) en el tipo penal. En este sistema la culpabilidad tiene otra connotación; se concibe como un juicio de reproche que se hace al autor de una conducta antijurídica, por haber actuado en contra de lo que exige la norma, pudiendo haberlo hecho de otra manera, por tanto, la responsabilidad penal está compuesta de la conciencia de la antijuricidad y de la culpabilidad. 
Este sistema de enjuiciamiento plantea una mayor rigidez en el desarrollo del procedimiento penal, pero bajo circunstancias muy distintas a las que prevalecían en nuestro país. En la mayoría de los países en los que este sistema opera las funciones de investigación policiaca de acusación, de procesamiento y de readaptación social se encomiendan a distintos órganos del Poder Judicial en una enorme gama de matices y formas, que van desde la comunicación como forma legal de garantizar el éxito de una investigación, o la prisión preventiva para efectos de investigación antes de la acusación, por varios días, semanas o meses, hasta una gran libertad para la emisión de órdenes de aprehensión, en ocasiones sin la formalidad de un escrito, condiciones procesales que no existían ni existen en nuestro país.

Con los cambios registrados a partir de 1993 se abandonó la figura del cuerpo del delito y se sustituyó por la de los elementos del tipo penal para que el Ministerio Público ejerciera la acción penal y solicitase la correspondiente orden de aprehensión, así como para que el juez emitiera un auto de formal prisión o de sujeción a proceso. La ley secundaria estableció como requisitos los siguientes: la existencia de la correspondiente acción y de la lesión o, en su caso, el peligro a que había sido expuesto el bien jurídico protegido; la forma de intervención de los sujetos activos; y la realización dolosa o culposa de la acción u omisión. Se determinó que deberían de acreditarse, si el tipo lo requiriese a) las calidades del sujeto activo y del pasivo; b) el resultado y su atribuibilidad a la acción u omisión; c) el objeto material; d) los medios utilizados; e) las circunstancias de lugar, tiempo, modo y ocasión; f) los elementos normativos; g) los elementos subjetivos específicos y h) las demás circunstancias que la ley previera.

De conformidad con estas disposiciones, el Ministerio Público necesariamente tenía que comprobar que el agente se había propuesto un fin delictivo, es decir, la comisión de un delito, que había elegido los medios idóneos para su ejecución y que había previsto la causalidad correspondiente al fin ya determinado por medio de la conducta desplegada. Como se aprecia, se tenía que acreditar tanto los elementos objetivos como los subjetivos y los normativos, es decir, se exigieron al Ministerio Público requisitos más complejos y que resultaban excesivos en fase de averiguación previa. En los criterios emitidos por la Suprema Corte de Justicia de la Nación se especificó claramente que en el auto de formal prisión 
debían estar acreditados todos y cada uno de los elementos constitutivos del tipo penal, además de señalar las modificativas o calificativas del delito por el cual se consignaba a un "probable responsable". Bajo estas condiciones, la instrucción perdió también su finalidad porque en ella lo que realmente estaba a juicio era la calidad técnica de la actuación del Ministerio Público, con lo que se dejó a un lado la verdad jurídica sobre la conducta criminal. En la averiguación y en la preinstrucción prácticamente se resolvía el asunto.

La acreditación plena de los elementos del tipo penal en fase indagatoria significó, desde luego, un serio obstáculo para la actividad ministerial, ya que no obstante de que en la integración de la misma se allegaba un cúmulo de pruebas al juzgador para acreditar los elementos del tipo penal del delito, estas pruebas si bien demostraban la existencia de los elementos objetivos del tipo penal no eran suficientes a la luz de las exigencias de la ley para acreditar los elementos subjetivos y normativos requeridos. La dificultad técnica obligaba a decretar la libertad de los inculpados con la cuota correspondiente de indignación social y la percepción de que el Estado estaba fomentando la impunidad.

La respuesta a esta crítica situación se dio en diciembre de 1997, cuando el titular del Ejecutivo Federal envió a la Cámara de Senadores, en funciones de órgano revisor, una iniciativa de reformas a los artículos 16, 19, 20, 22 y 123, apartado B, fracción XIII, de la Constitución Política, cuyo propósito consistió en hacer más eficiente la procuración de justicia en México. El anteproyecto fue impulsado en mucho por la Procuraduría General de la República

La iniciativa planteó flexibilizar los requisitos establecidos en el artículo 16 constitucional para obtener la orden de aprehensión, considerando suficientes la acreditación de la probable existencia de los elementos objetivos del tipo penal, así como la probable responsabilidad del indiciado; con ello se consideraba restaurado el equilibrio entre la acción persecutoria del delito y los derechos del justiciable y eficientada la acción de las autoridades procuradoras de justicia.

En cuanto a las modificaciones propuestas por el Ejecutivo al artículo 19 constitucional, se señaló la necesidad de modificar el segundo párrafo para que en la emisión de un auto de formal prisión se acreditara la plena existencia de los elementos del delito, así como la probable responsabilidad. Las exigencias probatorias a cargo del Ministerio Público no se 
reducirían con la reforma, sino que se cumplirían en las etapas procesales adecuadas.

Por lo que toca al artículo 22 constitucional se propuso crear la figura de la aplicación en beneficio del Estado de los instrumentos, objetos o productos de un delito, con lo que se atacaría el poder económico de la delincuencia organizada; con ello se pretendía evitar que los recursos de procedencia ilícita siguieran reproduciendo actividades ilícitas.

La aplicación procedería de conformidad con la iniciativa en los casos de delitos graves y delincuencia organizada, toda vez que sería decretada por autoridad judicial, después de seguirse un procedimiento en el que hubiesen sido observadas las formalidades de ley. La propuesta estableció dentro de los bienes susceptibles de aplicación no solamente los que fuesen propiedad o posesión del inculpado, sino también aquellos sobre los cuales se condujese como tal, aun cuando se hubieran transmitido a terceros, salvo que éstos acreditasen ser poseedores o adquirentes de buena fe.

Uno de los aspectos esenciales para que la función de seguridad pública y la procuración de justicia se desarrollaran de conformidad con los principios constitucionales de legalidad, eficiencia, profesionalismo y honradez, consistía en establecer con claridad la naturaleza del vínculo jurídico que unía al Estado con los miembros de los cuerpos de seguridad pública, por lo que la iniciativa sugirió la reforma al artículo 123, apartado B, fracción XIII.

De acuerdo con la interpretación jurisprudencial, la relación del Estado con sus empleados es de naturaleza administrativa, sin embargo, en beneficio y protección de los empleados del Estado ésta se transformó con objeto de equiparla a un vínculo de índole laboral, constituyéndose el Estado en una especie de patrón sui generis. La relación específica entre los militares, marinos, miembros de los cuerpos de seguridad pública y el personal del servicio exterior y del Estado, quedó al margen de esta equiparación, ya que de conformidad con lo dispuesto por la fracción XIII, apartado $\mathrm{B}$, del artículo 123 constitucional, dicha relación se rige por sus propias leyes y no por la Ley Federal de los Trabajadores al Servicio del Estado.

Para definir la naturaleza de la relación, la reforma propuso que los miembros de las instituciones de seguridad pública fueran considerados como trabajadores de confianza y se rigiesen conforme a sus propias 
leyes, gozando de las medidas de protección al salario y los beneficios de la seguridad social.

Para salvaguardar los fines de la seguridad pública, contar con mejores elementos y tener la posibilidad real de adecuar conforme a derecho las estructuras policiacas en beneficio de la sociedad mexicana, la iniciativa planteó que los miembros de las instituciones o cuerpos de seguridad pública no tendrían acción de reinstalación para el caso de baja, cese, destitución, remoción, separación o terminación de los efectos del nombramiento. Con esto se pretendió dotar a las corporaciones policiacas de herramientas que les permitieran depurar a los cuerpos de seguridad pública. La reforma propuesta no anularía el servicio civil de carrera, su propósito era garantizar que la función de seguridad pública se desarrollara con estricto apego a los principios constitucionales de legalidad, eficiencia, profesionalismo y honradez.

La iniciativa fue sometida a un amplio debate nacional. La Cámara de Senadores organizó varios foros de consulta con asociaciones de abogados, catedráticos, empresarios y organizaciones cívicas, para darla a conocer y fue presentada a los procuradores de justicia de todas las entidades. En octubre de 1998 las Comisiones Unidades de Puntos Constitucionales, de Justicia y de Estudios Legislativos de la Cámara de Senadores emitieron el dictamen correspondiente, en el que se contienen modificaciones a la iniciativa del Ejecutivo y suprimiéndose la propuesta de modificación al artículo 20 constitucional.

Las Comisiones propusieron, a la vez, una serie de modificaciones a la misma, dentro de las que destacó la recuperación del concepto "cuerpo del delito". En las referencias a los artículos 16 y 19 constitucionales, el dictamen señaló que el texto constitucional no debía seguir ninguna corriente doctrinal, y que en la determinación de los requisitos exigibles para librar una orden de aprehensión y un auto de formal prisión debía buscarse un equilibrio entre los derechos de los ciudadanos y la facultad de la autoridad para perseguir y castigar delitos, lo que se lograba con el restablecimiento del concepto de cuerpo del delito anterior a la reforma de 1993. El documento fue contundente al determinar que es en el proceso penal donde se da la amplitud probatoria, por lo que es materia de éste, y a la sentencia definitiva corresponde la acreditación plena del hecho delictivo y la responsabilidad del acusado. 
Así fue como se asentó que para librar una orden de aprehensión se requeriría que existiesen datos que acreditaran el cuerpo del delito y la probable responsabilidad del indiciado, es decir, que de los medios probatorios existentes se dedujese fundamentalmente la participación del indiciado en el hecho delictuoso. Con ello se reconoció que en las fases iniciales del proceso penal el grado de convicción del juez no tiene que ser pleno, sino que basta el apoyo de datos que hagan probable la responsabilidad para que se libre una orden de aprehensión.

En congruencia con el texto del artículo 16, fue también modificada la iniciativa de reformas al artículo 19 definiéndose los requisitos específicos necesarios para que el juez emitiera un auto de formal prisión, como son la expresión del delito que se impute al acusado; el lugar, tiempo y circunstancias de ejecución, así como los datos que arroje la averiguación previa, los que deberán ser bastantes para comprobar el cuerpo del delito y hacer probable la responsabilidad del indiciado.

Por cuanto toca al artículo 22 constitucional, se agregaron algunos supuestos a los originales asentados, quedando la redacción de la manera siguiente:

No se considerará confiscación la aplicación a favor del Estado de bienes asegurados que causen abandono en los términos de las disposiciones aplicables. La autoridad judicial resolverá que se apliquen a favor del Estado los bienes que hayan sido asegurados con motivo de una investigación o proceso que se sigan por delitos de delincuencia organizada, cuando se ponga fin a dicha investigación o proceso, sin que haya un pronunciamiento sobre los bienes asegurados. La resolución judicial se dictará previo procedimiento en el que se otorgue audiencia a terceros y se acredite plenamente el cuerpo del delito previsto por la ley como de delincuencia organizada, siempre y cuando se trate de bienes respecto de los cuales el inculpado en la investigación o proceso citados haya sido poseedor o propietario o se haya conducido como tales, independientemente de que hubieran sido transferidos a terceros, salvo que éstos acrediten que son poseedores o adquirientes de buena fe.

Sobre la reforma propuesta a la fracción XIII, del apartado B, del artículo 123 constitucional, en el dictamen se reconoció la necesidad de que el Estado dispusiese de un margen de acción que evitara comprometer la seguridad nacional en atención al ejercicio de ciertos derechos laborales de los miembros de las instituciones de seguridad pública. Se pretendió erradicar el serio problema que para las procuradurías significa 
dar el combate a la delincuencia que actúa en las calles y a la que se ha enquistado en las estructuras institucionales y que por lo mismo es tan peligrosa o más que la que abiertamente se reconoce como transgresora del orden público. Los malos elementos que amparados en un nombramiento y una placa abusan de su autoridad y aprovechan la función pública y el cargo que ostentan para delinquir, deben ser frontalmente combatidos, a ello se debe mucha de la desconfianza que la sociedad siente por las instituciones procuradoras de justicia y el desprestigio de los cuerpos ministeriales policiacos.

La redacción definitiva del precepto quedó de la siguiente manera:

Los militares, marinos, personal del servicio exterior, agentes del Ministerio Público y los miembros de las instituciones policiales, se regirán por sus propias leyes.

Los miembros de las instituciones policiales de los municipios, entidades federativas, del Distrito Federal, así como de la Federación, podrán ser removidos de su cargo si no cumplen con los requisitos que las leyes vigentes en el momento de la remoción señalen para permanecer en dichas instituciones, sin que proceda su reinstalación o restitución, cualquiera que sea el juicio o medio de defensa para combatir la remoción y, en su caso, sólo procederá la indemnización. La remoción de los demás servidores públicos a que se refiere la presente fracción, se regirá por lo que dispongan los preceptos legales aplicables.

Esta es, a grandes trazos, la reforma constitucional en materia penal que acaba de ser publicada y entrado ya en vigor en nuestro país. En el tintero del Honorable Poder Legislativo se ha quedado la propuesta de modificación al artículo 20 de nuestra ley fundamental, seguramente por una lectura incorrecta de lo que hasta ahora se pretendía buscar con su enmienda, subrayando que con esa reforma jamás se pretendió instaurar en México los juicios en ausencia. La pretensión era castigar la evasión de la justicia. No es posible que en este México de finales del siglo la legislación en vez de reprochar que los presuntos responsables evadan la acción de la justicia se les privilegie, se les auspicie y se les aliente.

De las 50,000 órdenes de aprehensión pendientes de cumplir por parte de la Procuraduría General de la República 14,000 de ellas son órdenes de reaprehensión, es decir, de presuntos responsables que por una razón $\mathrm{u}$ otra, pero sobre todo por la fragilidad de nuestra legislación, han logrado hasta hoy evadir la acción de la justicia; no es justo que desde la propia 
médula de la ley se esté impulsando la evasión de la justicia en vez de lograr que se queden comprometidos los presuntos responsables a encarar un verdadero proceso legal.

Jorge MADRAZO CUÉLLAR 